\title{
BMJ Open Housing type after the Great East Japan Earthquake and loss of motor function in elderly victims: a prospective observational study
}

\author{
Kumiko Ito, ${ }^{1}$ Yasutake Tomata, ${ }^{2}$ Mana Kogure, ${ }^{2}$ Yumi Sugawara, ${ }^{2}$ \\ Takashi Watanabe, ${ }^{2}$ Tadayoshi Asaka, ${ }^{3}$ Ichiro Tsuji ${ }^{2}$
}

To cite: Ito K, Tomata $Y$ Kogure $\mathrm{M}$, et al. Housing type after the Great East Japan Earthquake and loss of motor function in elderly victims: a prospective observational study. BMJ Open 2016;6: 012760 . doi:10.1136/bmjopen-2016012760

- Prepublication history for this paper is available online. To view these files please visit the journal online (http://dx.doi.org/10.1136/ bmjopen-2016-012760).

$\mathrm{KI}$ and $\mathrm{YT}$ contributed equally.

Received 21 May 2016

Revised 7 October 2016

Accepted 13 October 2016

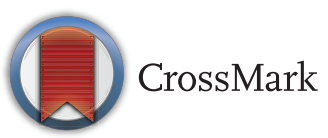

${ }^{1}$ Department of Rehabilitation Science, Graduate School of Health Sciences, Hokkaido University, Sapporo, Japan ${ }^{2}$ Division of Epidemiology, Department of Health Informatics and Public Health, Tohoku University School of Public Health, Graduate School of Medicine, Sendai, Japan

${ }^{3}$ Department of Rehabilitation Science, Faculty of Health Sciences, Hokkaido University, Sapporo, Japan

Correspondence to Dr Yasutake Tomata; y-tomata@med.tohoku.ac.jp

\begin{abstract}
Objective: Previous studies have reported that elderly victims of natural disasters might be prone to a subsequent decline in motor function. Victims of the Great East Japan Earthquake (GEJE) relocated to a wide range of different types of housing. As the evacuee lifestyle varies according to the type of housing available to them, their degree of motor function loss might also vary accordingly. However, the association between postdisaster housing type and loss of motor function has never been investigated. The present study was conducted to investigate the association between housing type after the GEJE and loss of motor function in elderly victims.
\end{abstract}

Methods: We conducted a prospective observational study of 478 Japanese individuals aged $\geq 65$ years living in Miyagi Prefecture, one of the areas most significantly affected by the GEJE. Information on housing type after the GEJE, motor function as assessed by the Kihon checklist and other lifestyle factors was collected by interview and questionnaire in 2012. Information on motor function was then collected 1 year later. The multiple logistic regression model was used to estimate the multivariate adjusted ORs of motor function loss.

Results: We classified $53(11.1 \%)$ of the respondents as having loss of motor function. The multivariate adjusted OR (with $95 \% \mathrm{Cl}$ ) for loss of motor function among participants who were living in privately rented temporary housing/rental housing was 2.62 (1.10 to $6.24)$ compared to those who had remained in the same housing as that before the GEJE, and this increase was statistically significant.

Conclusions: The proportion of individuals with loss of motor function was higher among persons who had relocated to privately rented temporary housing/rental housing after the GEJE. This result may reflect the influence of a move to a living environment where few acquaintances are located (lack of social capital).

\section{INTRODUCTION}

With the ageing of societies around the world, loss of motor function among elderly

\section{Strengths and limitations of this study}

- This study is the first to have reported an association between housing type after the Great East Japan Earthquake and loss of motor function.

- This study examined the chronic effect on motor function 1 year after the disaster.

- A larger sample size would have been desirable to examine the influence of the various types of housing.

- As this study was based on data from only one city (Ishinomaki), its external validity was not clear.

people affected by natural disasters is becoming a significant public health issue. ${ }^{1-3}$ In areas that were seriously affected by the tsunami caused by the Great East Japan Earthquake (GEJE) on 11 March 2011, the prevalence of functional disability among the elderly population increased steeply during the following year, ${ }^{4}$ suggesting the influence of not only injury and acute causes, but also chronic factors.

One possible reason for this chronic increase of functional disability among the elderly might be the evacuee lifestyle, which is a problem specific to disaster victims. Approximately 130000 buildings were completely destroyed by the tsunami that accompanied the GEJE, and many homes were lost. ${ }^{5}$ Three years after the disaster, 260000 people remained displaced from their homes. ${ }^{6}$ Studies have indicated that relocated individuals are more likely to experience psychological morbidity after natural disasters. However, the effect of an evacuee lifestyle on health varies according to the type of housing to which people have relocated. Studies have indicated that elderly people who have relocated to temporary housing have a worse perception of their quality of 
life than others, ${ }^{8}$ and that those who have relocated to temporary trailer or newly purchased/rented residence are more likely to experience post-traumatic stress disorder symptoms and psychological distress. ${ }^{9-11}$ Possible reasons for this housing-related effect on health include differences in both living environment and social support from relatives and friends. ${ }^{7} 8$ Victims of the GEJE have relocated to a wide range of different housing types, including temporary housing, the homes of relatives and so on. ${ }^{12}$ Prefabricated temporary housing and privately rented temporary housing were provided by the government as emergency temporary housing. ${ }^{13}$ However, these two types of housing were located in different areas, which meant that ease of access to facilities such as hospitals and supermarkets varied. As prefabricated temporary housing was erected on unused, undeveloped land, there were no facilities or public transport services in the surrounding areas. Therefore, those who were living in prefabricated temporary housing found it difficult to access facilities. ${ }^{14}$ In contrast, most privately rented temporary housing was likely to be located in urban areas with easy access to such facilities. Therefore, people living in prefabricated temporary housing might have been discouraged from going out, thus decreasing its frequency. The various procedures required for relocation to these two types of housing might also have affected social support from relatives and friends in different ways. In some places, people were relocated to prefabricated temporary housing on the basis of administrative district, ${ }^{15}$ meaning that many people would have had relatives and friends living nearby. People who relocated to privately rented temporary housing, however, did so as individual households, ${ }^{15}$ meaning that they did not have relatives or friends living nearby; therefore, their environment would have lacked social support from relatives and friends. In environments with little social support from relatives and friends, people have few opportunities to go out because they lack local company for sharing hobbies or other activities; therefore, they tend to remain at home. There has also been concern that absence of psychological support from relatives and friends reduces individual motivation, again discouraging people from going out. These differences in living environment and social support from relatives and friends mean that displaced elderly people go out less frequently and there is a decrease in physical activity. This leads to a decline in musculoskeletal and cardiopulmonary function, and possibly motor function. ${ }^{16}$ If motor function declines, it becomes even more troublesome to go out, creating a vicious cycle that leads to further decline in motor function. ${ }^{14}$

Our hypothesis, therefore, is that elderly people who have relocated to temporary housing after a natural disaster might be prone to a decline in motor function. To the best of our knowledge, however, no study has yet reported an association between relocation to a specific housing type and loss of motor function. The aim of the present study was to investigate the association between the type of housing to which elderly people relocated after the GEJE and loss of motor function.

\section{METHODS}

\section{Participants}

To assess the state of health and lifestyle habits of victims of the GEJE, health surveys were carried out by Tohoku University Graduate School of Medicine every 6 months from June 2011 after the disaster. These surveys, employing interviews and self-administered questionnaires, were carried out in two coastal towns, Oshika and Ogatsu, located in the area of Ishinomaki City, Miyagi Prefecture. The study population comprised 2504 men and women aged $\geq 65$ years (as of 31 March 2012) on the basis of data taken from the Basic Resident Registration system of the Oshika and Ogatsu towns of Ishinomaki City, or data from previous health surveys that included known addresses in June and July 2012 (figure 1). We excluded 1605 elderly questionnaire nonrespondents, 85 persons who did not consent to participate, 17 persons who either did not indicate their current housing type or answered 'Other', and 16 persons who did not respond to at least one of the items in the Kihon checklist, leaving a total of 781 persons. Thereafter, we excluded 303 persons who did not provide valid answers for the Kihon checklist in the subsequent health survey carried out in May and July 2013.

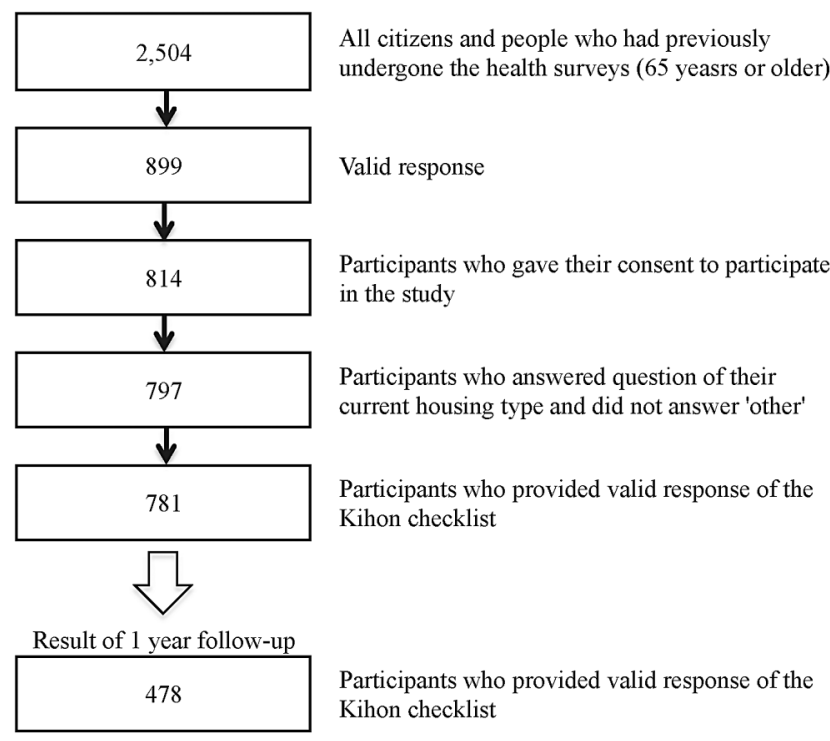

Figure 1 Flow chart of the study participants. The study population comprised 2504 men and women aged $\geq 65$ years (as of 31 March 2012) who were living in Oshika and Ogatsu towns of Ishinomaki City, Miyagi Prefecture, Japan, or who had previously undergone health surveys that included known addresses. The surveys for this study were carried out using interviews and self-administered questionnaires in June-July 2012 and May-July 2013. This figure details the flow of the study participants. A total of 478 responses were analysed for the purposes of this study. 
Thus, 478 responses were analysed for the purposes of this study.

\section{Housing type after the GEJE (exposure measure)}

With respect to housing after the GEJE, participants were asked to circle the option that best described their current main place of residence from among the following: same housing as that before the GEJE (no relocation), prefabricated temporary housing, rental housing, the homes of relatives, reconstructed housing or privately rented temporary housing. Of the baseline housing categories, rental housing and privately rented temporary housing were placed in the same category because they were considered to represent the same form of housing, and the following five categories were used as exposure variables: same housing as that before the GEJE, prefabricated temporary housing, privately rented temporary housing/rental housing, the homes of relatives or reconstructed housing.

Emergency temporary housing, which included prefabricated temporary housing and privately rented temporary housing, was considered to be housing provided by the government to secure temporary accommodation for people who were unable to continue living in their own homes after the GEJE. ${ }^{13}$ The local government defined the temporary housing entry criteria as 'any person who has lost a place of residence due to the disaster and is having difficulty securing a new dwelling house for long-term occupation through his/her own efforts (eg, household economy)' without any distinction regarding the type of temporary housing.

\section{Same housing as that before the GEJE}

The same housing as that before the GEJE referred to continuing to live in the same housing after the GEJE as that before the disaster.

\section{Prefabricated temporary housing}

Prefabricated temporary housing was characterised by high humidity, poor insulation and air tightness, thin internal walls that were far from soundproof and poor access. ${ }^{14}$ In some cases, residents were moved into prefabricated temporary housing on the basis of administrative district rather than by single households in order to maintain existing networks of social support from relatives and friends. ${ }^{15}$

\section{Privately rented temporary housing}

Privately rented temporary housing comprised existing privately rented housing that had been rented by the government and used as emergency temporary housing. ${ }^{17}$ In this study, privately rented temporary housing also included leased public housing. There were two reasons for the use of privately rented temporary housing. One was that a shorter time was required before residents could move in because it was already in use as housing. The other was that privately rented temporary housing was cheaper than prefabricated temporary housing because no construction costs were necessary. ${ }^{15}$

\section{Motor function (outcome measure)}

The study outcome, motor function, was assessed in terms of the following five yes-or-no questions from the motor function score of the Kihon checklist: 'Can you climb stairs without holding onto a handrail or wall?', 'Can you get up from a chair without grabbing something?', 'Are you able to walk for about 15 minutes?', 'Have you fallen in the past year?' and 'Are you very worried about falling?'. Previous validation studies have reported that the motor function score of the Kihon checklist is correlated with objective measurements of motor function, and predicts incident functional disability. ${ }^{18-20}$ The responses were scored as 1 point for each negative response, and the total score for all five questions $(0-5$ points $)$ was calculated.

\section{Covariates}

This survey included questions about present illness (stroke, myocardial infarction, kidney disease and cancer), body weight, height, smoking, drinking, subjective health, insomnia, social capital, psychological distress, social networks, subjective household economic status, physical activity and outdoor physical activity before the GEJE. Body weight and height were measured. Subjective health was assessed by asking the question 'What is your state of health?' for which available responses were 'Very good', 'Somewhat good', 'Not good' and 'Bad'. Insomnia was assessed using the Athens Insomnia Scale. ${ }^{21} 22$ Social capital was assessed by asking the following four questions: 'Do the people around you help each other?', 'Can you trust the people around you?', 'Do the people around you greet one another?' and 'If some sort of problem occurs, do the people around you work together to try and solve it?'. The participants were asked to choose one of the following responses: 'Not at all', 'Not really', 'Neither', 'True to some extent' and 'Very true'. The answers were scored from 0 to 4 points on a scale of increasing positivity, and the total score for all four questions (0-16 points) was calculated. Psychological distress was assessed using the Kessler 6-Item Psychological Distress Scale (K6). ${ }^{23}{ }^{24}$ Social networks (family and friendship ties) were assessed using the Lubben Social Network Scale-6. ${ }^{25}{ }^{26}$ Subjective household economic status was assessed by asking the question 'How do you feel about your current household economy?' for which available responses were 'Poorest', 'Poorer', 'Poor' and 'Fair'. Physical activity was assessed in terms of the following three parameters: daily physical activity, frequency of going out and walking time. ${ }^{27}$ These items were scored from 1 to 5 points on a scale of increasing physical activity, and the total score for all three questions (3-15 points) was calculated. Outdoor physical activity before the GEJE was assessed by asking the question 'How physically active were you during the day?' for which 
available responses were 'I was very active both inside and outside the house', 'I was very active indoors', 'I spent a lot of time sitting', 'I sometimes used to lie down' and 'I spent most of the time lying down'. These data were taken from two prebaseline surveys (JuneAugust 2011 and October 2011-February 2012).

\section{Statistical analysis}

Baseline characteristics were evaluated by using the $\chi^{2}$ test for categorical variables and ANOVA for continuous variables. 'Loss of motor function' was defined as a change equal to or greater than $1 \mathrm{SD}$ (2 points) from the mean change 1 year after the baseline in the motor function score of the Kihon checklist. We used multivariate logistic regression analysis to calculate the OR and 95\% CI for having loss of motor function according to the categories of housing type after the GEJE. We established respondents living in the same housing as that before the GEJE as the reference category and investigated the association between the housing type after the GEJE and loss of motor function by using the following models.

Model 1 was adjusted for sex and age (continuous variable). Model 2 was adjusted for sex, age, town (Oshika or Ogatsu), smoking (smoker, non-smoker or missing), drinking (drinker, non-drinker or missing), body mass index (in $\mathrm{kg} / \mathrm{m}^{2} ;<18.5,18.5-24.9$, $\geq 25.0$ or missing), the motor function score of the Kihon checklist at the baseline (continuous variable) and outdoor physical activity before the GEJE (very active both inside and outside the house, not active outside the house or missing). Motor function score of the Kihon checklist at the baseline was taken into account because it was assumed that it would impact on the degree of change in motor function over time. ${ }^{28}$ Outdoor physical activity before the GEJE was taken into account because it was assumed that people who had been very physically active before the disaster would have retained high levels of physical activity whatever their housing type, thus affecting motor function outcome.

We stratified the responses by sex (men or women) and age ( $<75$ years or $\geq 75$ years), and calculated their interactions with housing type after the GEJE. When calculating these interactions, we used cross-product terms of housing type after the GEJE with sex or age. In addition, we performed two exclusion analyses. One excluded participants with low motor function $(\geq 4$ points for the motor function score of the Kihon checklist) at the baseline, and the other excluded participants who had some form of illness (stroke, myocardial infarction, kidney disease or cancer) at the baseline. The multivariate adjustment model (Model 2) was used for analyses of interactions and exclusion analyses.

All data were analysed using IBM SPSS statistics software V.22 (IBM Japan, Tokyo, Japan). All statistical tests described here were 2-sided, and differences at $\mathrm{p}<0.05$ were accepted as significant.

\section{RESULTS}

\section{Basic characteristics}

The mean age $\pm \mathrm{SD}$ of the participants was $73.4 \pm 5.4$ years; $63.0 \%$ were aged $<75$ years and $47.1 \%$ were men. With regard to housing type at the baseline, most of the participants $(195 ; 40.8 \%)$ stated that they were living in the same housing as that before the GEJE, 184 (38.5\%) were living in prefabricated temporary housing, 64 $(13.4 \%)$ in privately rented temporary housing/rental housing, $26(5.4 \%)$ in the homes of relatives and 9 $(1.9 \%)$ in reconstructed housing. We considered that a total of 53 participants $(11.1 \%)$ had loss of motor function.

The baseline characteristics of participants according to the type of housing they were living in after the GEJE are shown in table 1. Participants living in the same housing as that before the GEJE were less likely to have low physical activity. Participants living in prefabricated temporary housing were more likely to have stroke as a present illness, and to have low physical activity, followed by those living in privately rented temporary housing/rental housing. Participants living in privately rented temporary housing/rental housing were more likely to be men, to be current smokers, to have kidney disease or cancer as a present illness, to have subjectively poor health and subjectively poor household economic status, to suffer from psychological distress and insomnia, to have little social capital and low motor function, and to have low physical activity and high outside physical activity before the GEJE. Participants living in the homes of relatives were more likely to have marginal friendship ties, and to have myocardial infarction as a present illness. Participants living in reconstructed housing were more likely to be current alcohol drinkers.

\section{Association between housing type after the GEJE and loss of motor function}

The association between housing type after the GEJE and loss of motor function is shown in table 2 . Participants who showed loss of motor function accounted for $10.3 \%$ of those living in the same housing as that before the GEJE, $10.3 \%$ of those in prefabricated temporary housing, $20.3 \%$ of those in privately rented temporary housing/rental housing, 3.8\% of those in the homes of relatives and $0 \%$ of those in reconstructed housing. In comparison with participants who were living in the same housing as that before the GEJE, the multivariate adjusted OR (95\% CI) for loss of motor function among those in privately rented temporary housing/rental housing was 2.62 (1.10 to 6.24$)$, which represented a significant increase. There was no significant association among those in prefabricated temporary housing (OR: $1.05,95 \%$ CI 0.52 to 2.12 ) or the homes of relatives (OR: $0.37,95 \%$ CI 0.04 to 3.14 ). The Hosmer-Lemeshow goodness of model fit test did not indicate significance $(\mathrm{p}=0.589)$. 
Table 1 Baseline characteristics ( $n=478$ participants)

\begin{tabular}{|c|c|c|c|c|c|c|}
\hline & \multicolumn{5}{|c|}{ Housing type after the GEJE } & \multirow[b]{2}{*}{ p Valueł } \\
\hline & $\begin{array}{l}\text { Same as that } \\
\text { before the } \\
\text { GEJE }\end{array}$ & Temporary* & $\begin{array}{l}\text { Privately rented } \\
\text { temporaryt/rental }\end{array}$ & Relatives & Reconstructed & \\
\hline$n$ & 195 & 184 & 64 & 26 & 9 & \\
\hline Male sex (\%) & 41.0 & 50.0 & 59.4 & 42.3 & 44.4 & 0.105 \\
\hline Age $(y)$ & $74.1 \pm 5.5 \S$ & $72.8 \pm 5.4$ & $72.8 \pm 4.7$ & $73.5 \pm 5.9$ & $72.1 \pm 5.2$ & 0.179 \\
\hline BMI $\left(\mathrm{kg} / \mathrm{m}^{2}\right)$ & $24.1 \pm 3.3$ & $23.9 \pm 3.1$ & $24.4 \pm 2.7$ & $24.8 \pm 3.1$ & $23.0 \pm 2.3$ & 0.622 \\
\hline \multicolumn{7}{|l|}{ Present illness (\%) } \\
\hline Stroke & 2.1 & 2.2 & 1.6 & 0.0 & 0.0 & 0.936 \\
\hline Myocardial infarction & 5.1 & 12.0 & 9.4 & 23.1 & 22.2 & 0.013 \\
\hline Kidney disease & 1.0 & 0.5 & 3.1 & 0.0 & 0.0 & 0.479 \\
\hline Cancer & 3.6 & 1.6 & 4.7 & 0.0 & 0.0 & 0.509 \\
\hline Current smoker (\%) & 4.1 & 11.5 & 14.5 & 12.0 & 0.0 & 0.031 \\
\hline Current alcohol drinker (\%) & 21.1 & 35.3 & 41.9 & 38.5 & 57.1 & 0.002 \\
\hline Poor subjective health (\%) & 16.9 & 23.9 & 43.8 & 3.8 & 0.0 & $<0.001$ \\
\hline $\begin{array}{l}\text { Subjectively poor household } \\
\text { economic status (\%) }\end{array}$ & 36.4 & 48.4 & 69.4 & 26.9 & 44.4 & $<0.001$ \\
\hline Psychological distress (\%)ף & 2.6 & 6.6 & 12.9 & 7.7 & 0.0 & 0.033 \\
\hline High risk of insomnia $(\%)^{\star \star}$ & 24.5 & 32.4 & 45.0 & 26.9 & 12.5 & 0.027 \\
\hline Little social capital (\%)†† & 5.7 & 5.4 & 16.1 & 11.5 & 0.0 & 0.035 \\
\hline $\begin{array}{l}\text { High outside physical activity } \\
\text { before the GEJE (\%) }\end{array}$ & 83.2 & 83.4 & 89.1 & 71.4 & 88.9 & 0.481 \\
\hline 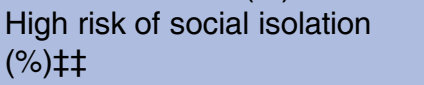 & 13.4 & 15.4 & 9.5 & 19.2 & 11.1 & 0.725 \\
\hline Marginal family ties (\%)§§ & 9.2 & 9.3 & 4.7 & 7.7 & 0.0 & 0.671 \\
\hline Marginal friendship ties (\%)ףा & 20.1 & 21.4 & 17.5 & 38.5 & 22.2 & 0.259 \\
\hline $\begin{array}{l}\text { Low physical activity at the } \\
\text { baseline }(\%)^{\star \star \star}\end{array}$ & 17.5 & 31.7 & 35.5 & 26.9 & 22.2 & 0.010 \\
\hline Low motor function (\%)††† & 23.6 & 16.3 & 25.0 & 23.1 & 0.0 & 0.174 \\
\hline \multicolumn{7}{|c|}{  } \\
\hline
\end{tabular}

\section{Stratified analyses of the association between housing} type after the GEJE and loss of motor function

In this study, two stratified analyses of interaction by sex and age were performed (table 3). Housing type after the GEJE showed no interactions with sex or age. Two exclusion analyses were also performed (table 3). Analysis excluding participants with low motor function at the baseline revealed significant loss of motor function among those living in privately rented temporary housing/rental housing (multivariate adjusted OR 2.53 (95\% CI 1.06 to 6.03$)$ ). Analysis excluding participants in whom illness had been present at the baseline also revealed significant loss of motor function among those living in privately rented temporary housing/rental housing (multivariate adjusted OR 2.87 (95\% CI 1.15 to 7.17)).

\section{DISCUSSION}

In this prospective observational study, we investigated the association between housing type after the GEJE and loss of motor function among elderly people who were living in affected areas. One year after the disaster, the study participants were living in various types of housing: same housing as that before the GEJE, prefabricated temporary housing, privately rented temporary housing, rental housing, the homes of relatives and reconstructed housing. We found that elderly people who had relocated to privately rented temporary housing/rental housing showed significant loss of motor function. However, no such significant association was found for elderly people who had relocated to prefabricated temporary housing, the homes of relatives or reconstructed housing. 
Table 2 Association between housing type after the GEJE and loss of motor function

\begin{tabular}{|c|c|c|c|c|c|}
\hline \multirow[b]{2}{*}{$\mathbf{n}$} & \multicolumn{5}{|c|}{ Housing type after the GEJE } \\
\hline & $\begin{array}{l}\text { Same as that } \\
\text { before the GEJE } \\
195\end{array}$ & $\begin{array}{l}\text { Temporary } \\
184\end{array}$ & $\begin{array}{l}\text { Privately rented } \\
\text { temporary/rental } \\
64\end{array}$ & $\begin{array}{l}\text { Relatives } \\
26\end{array}$ & $\begin{array}{l}\text { Reconstructed } \\
9\end{array}$ \\
\hline \multicolumn{6}{|l|}{ Loss of motor function* } \\
\hline No. with loss & 20 & 19 & 13 & 1 & 0 \\
\hline $\begin{array}{l}\text { Proportion of those with } \\
\text { loss (\%) }\end{array}$ & 10.3 & 10.3 & 20.3 & 3.8 & 0.0 \\
\hline Model 1† & 1.00 (Reference) & $1.01(0.52$ to 1.96$) \ddagger$ & $2.22(1.02$ to 4.84$)$ & 0.35 (0.05 to 2.72$)$ & - \\
\hline Model $2 \S$ & 1.00 (Reference) & 1.05 (0.52 to 2.12$)$ & 2.62 (1.10 to 6.24$)$ & $0.37(0.04$ to 3.14$)$ & - \\
\hline \multicolumn{6}{|c|}{$\begin{array}{l}{ }^{*} \text { A change equal to or }>1 \text { SD ( } 2 \text { points) from the mean change in the motor function score of the Kihon checklist } 1 \text { year after the baseline. } \\
\text { †Model } 1 \text { was adjusted for age and for sex (continuous variable). } \\
\text { †OR; } 95 \% \mathrm{Cl} \text { in parentheses (all such values). } \\
\text { §Model } 2 \text { was adjusted as for model } 1 \text { plus town (Oshika or Ogatsu), smoking (smoker, non-smoker or missing), drinking (drinker, non-drinker } \\
\text { or missing), body mass index (in } \mathrm{kg} / \mathrm{m}^{2} ;<18.5,18.5-24.9, \geq 25.0 \text { or missing), the motor function score of the Kihon checklist at the baseline } \\
\text { (continuous variable), and outdoor physical activity before the GEJE (very active both inside and outside the house, not active outside the } \\
\text { house or missing). } \\
\text { GEJE, Great East Japan Earthquake. }\end{array}$} \\
\hline
\end{tabular}

Previous studies have reported the health-related effect of living in privately rented temporary housing or rental housing. The prevalence of post-traumatic stress disorder is reportedly higher among individuals who have relocated to newly purchased/rented housing, ${ }^{9}$ furthermore, in Japan, it has been shown that the incidence of psychological distress among elderly people living in privately rented temporary housing is almost twice as high as that among those living in the community. ${ }^{10}{ }^{11}$ Although the present study had a different outcome, our results were consistent with those of previous studies in that people who had relocated to privately rented temporary housing/rental housing were in poorer health.

The present study considered both the ceiling effect and the effect of reverse causality. First, we were concerned that the main findings might be explained by the ceiling effect. ${ }^{29}$ If a large number of participants with high motor function scores (close to the maximum) at the baseline were still living in the same housing as that before the GEJE, their motor function score would not worsen. In such a case, loss of motor function would have been observed among those living in privately rented temporary housing/rental housing. However, even when participants with high motor function scores ( $\geq 4$ points) at the baseline were excluded, the significant association with privately rented temporary housing/rental housing was still observed. Therefore, it seemed unlikely that the main findings of the present study were explained by the ceiling effect. Second, we were concerned that the main findings might be attributable to reverse causality. More participants with a present illness might have relocated to privately rented temporary housing/rental housing located in urban areas in order to obtain easier access to medical institutions. It is therefore possible that reverse causality may have been responsible for the significant association observed for privately rented temporary housing/rental housing. To account for the effect of reverse causality, participants who already had an illness at the baseline were excluded, but the significant association with privately rented temporary housing/rental housing still remained. Therefore, it seemed unlikely that the main findings of the present study were also attributable to reverse causality.

Lack of social capital is another possible reason for the significantly higher rate of motor function loss that has been observed among participants living in privately rented temporary housing/rental housing. Participants living in privately rented temporary housing/rental housing included the highest proportion of individuals with little social capital $(16.1 \%$ at the baseline $)$, although the proportion of those with social isolation, including friendship ties, was not high (table 1). This low level of social capital associated with privately rented temporary housing/rental housing might have been attributable to the fact that people relocated by single households independently, whereas relocation to prefabricated temporary housing was organised according to administrative district. ${ }^{15}$ Participants relocated to privately rented temporary housing/rental housing also included the highest proportion of individuals with low physical activity at the baseline (table 1). Little social capital is known to be a risk factor for the physically inactive. ${ }^{30} 31$

For those living in prefabricated temporary housing, however, the OR was lower than for those living in privately rented temporary housing/rental housing, and there was no significant association. Only $5.4 \%$ of study participants living in prefabricated temporary housing reported having little social capital, being less than half the proportion of those living in privately rented temporary housing/rental housing who reported this problem. One reason for this may have been that relocation to prefabricated temporary housing was organised according to administrative district, ${ }^{15}$ and therefore 


\begin{tabular}{|c|c|c|c|c|c|c|}
\hline & \multicolumn{5}{|c|}{ Housing type after the GEJE } & \multirow[b]{2}{*}{ P-interaction } \\
\hline & $\begin{array}{l}\text { Same as that } \\
\text { before the GEJE }\end{array}$ & Temporary & $\begin{array}{l}\text { Privately rented } \\
\text { temporary/rental }\end{array}$ & Relatives & Reconstructed & \\
\hline \multicolumn{7}{|l|}{ Sex } \\
\hline Men $(n=225)$ & & & & & & 0.500 \\
\hline No. of participants & 80 & 92 & 38 & 11 & 4 & \\
\hline No. with loss (\%) & $9(11.3)$ & $10(10.9)$ & $7(18.4)$ & $0(0.0)$ & $0(0.0)$ & \\
\hline OR $(95 \% \mathrm{Cl})^{*}$ & 1.00 (Reference) & 0.99 (0.36 to 2.73$) \dagger$ & 2.13 (0.65 to 6.94$)$ & - & - & \\
\hline \multicolumn{7}{|l|}{ Women $(n=253)$} \\
\hline No. of participants & 115 & 92 & 26 & 15 & 5 & \\
\hline No. with loss (\%) & $11(9.6)$ & $9(9.8)$ & $6(23.1)$ & $1(6.7)$ & $0(0.0)$ & \\
\hline OR (95\% Cl) & 1.00 (Reference) & 1.12 (0.42 to 3.00$)$ & 3.58 (0.92 to 13.97$)$ & 0.59 (0.06 to 5.95$)$ & - & \\
\hline \multicolumn{7}{|l|}{ Age } \\
\hline$<75$ years $(n=301)$ & & & & & & 0.627 \\
\hline No. of participants & 110 & 126 & 43 & 16 & 6 & \\
\hline No. with loss (\%) & $10(9.1)$ & $12(9.5)$ & $10(23.3)$ & $0(0.0)$ & $0(0.0)$ & \\
\hline OR $(95 \% \mathrm{Cl})$ & 1.00 (Reference) & 1.07 (0.42 to 2.69$)$ & 2.44 (0.82 to 7.26$)$ & - & - & \\
\hline \multicolumn{7}{|l|}{$\geq 75$ years $(n=177)$} \\
\hline No. of participants & 85 & 58 & 21 & 10 & 3 & \\
\hline No. with loss (\%) & $10(11.8)$ & $7(12.1)$ & $3(14.3)$ & $1(10.0)$ & $0(0.0)$ & \\
\hline OR $(95 \% \mathrm{Cl})$ & 1.00 (Reference) & $1.41(0.41$ to 4.83$)$ & 3.86 (0.62 to 23.99$)$ & 1.64 (0.13 to 20.33$)$ & - & \\
\hline \multicolumn{7}{|c|}{ Except for participants with low motor function at the baseline $(n=448)$} \\
\hline No. of participants & 179 & 175 & 62 & 23 & 9 & \\
\hline No. with loss (\%) & $20(11.2)$ & $19(10.9)$ & $13(21.0)$ & $1(4.3)$ & $0(0.0)$ & \\
\hline OR $(95 \% \mathrm{Cl})$ & 1.00 (Reference) & 1.04 (0.52 to 2.09$)$ & $2.53(1.06$ to 6.03$)$ & $0.37(0.04$ to 3.17$)$ & - & \\
\hline \multicolumn{7}{|c|}{ Except for participants with illness (stroke, myocardial infarction, kidney disease and cancer) at the baseline $(n=411)$} \\
\hline No. of participants & 173 & 158 & 53 & 20 & 7 & \\
\hline No. with loss (\%) & 19 (11.0) & 19 (12.0) & $11(20.8)$ & $1(5.0)$ & $0(0.0)$ & \\
\hline OR $(95 \% \mathrm{Cl})$ & 1.00 (Reference) & 1.16 (0.57 to 2.36 ) & 2.87 (1.15 to 7.17$)$ & $0.47(0.06$ to 4.05$)$ & - & \\
\hline \multicolumn{7}{|c|}{$\begin{array}{l}\text { "Adjusted as for model } 2 \text { in table } 2 \text {. } \\
\text { tMultiple adjusted OR; } 95 \% \text { C Cin parentheses (all such values). } \\
\text { GEJE, Great East Japan Earthquake. }\end{array}$} \\
\hline
\end{tabular}


relatives and friends would have been living nearby. Assembly halls were also provided near areas of prefabricated temporary housing, ${ }^{13}$ which enabled disaster victims to socialise with each other and create new social networks. Support for elderly disaster victims was also facilitated by the creation of new social networks and exercise programmes offered by the government, hospitals, private organisations and universities. ${ }^{32}$ This type of support also offered opportunities for disaster victims to socialise among themselves, thereby alleviating their lack of social capital. Exercise classes might also have been directly helpful for prevention of motor function loss. ${ }^{33}$ Such support was offered mainly to people living in prefabricated temporary housing, and in fact there have been few reports of this sort of assistance being offered to people living in privately rented temporary housing/ rental housing or other types of housing. In practice, because of the laws designed to safeguard personal information in Japan, the government is unable to reveal information about the identity of residents living in privately rented temporary housing. This meant that if they did not appeal on their own, they would be unable to receive support from private organisations. ${ }^{15}$ This suggests that there may have been no significant association for prefabricated temporary housing because of the availability of social support from their surroundings.

In Japan, the housing policy being considered in the event of future large-scale disasters is to increase the number of people who are relocated to privately rented temporary housing if they can no longer remain in their own homes. However, our present analysis shows that relocating elderly people to privately rented temporary housing/rental housing has an adverse effect on their health. Therefore, future rehousing policies for elderly disaster victims will need to consider the issue of social capital.

This study had some limitations. First, the sample size was small, and this may have hindered adequate assessment of motor function loss in participants who were living in prefabricated temporary housing, in the homes of relatives or in reconstructed housing. Second, the external validity of our findings was unclear because this study was based on data from only a single city, Ishinomaki. Third, the Kihon checklist used in this study as an outcome measure has a narrow range of possible scores, which might have made changes difficult to detect, thereby rendering it insensitive as an index. Fourth, as 24 participants $(37.5 \%)$ who were living in privately rented temporary housing/rental housing at the baseline did not answer the question about housing type or relocated from privately rented temporary housing/rental housing 1 year later, the results might not have reflected the true effect of this form of housing on motor function. An analysis of only those participants who stated that they were living in the same type of housing at the baseline and 1 year later $(n=411)$ showed that the multivariate adjusted OR for privately rented temporary housing/rental housing was 2.09 (95\% CI 0.76 to 5.78), which tended to be higher, although the association did not reach statistical significance. Therefore, if all the participants who had relocated to privately rented temporary housing/rental housing could have been followed up, it is unlikely that the present results would have changed. Fifth, in this study, the rate of valid responses at the baseline was not high $(35.9 \%)$, and therefore our study population might not have included people who had a higher risk of motor function decline, thus leading to possible underestimation of the risk of motor function loss.

\section{CONCLUSIONS}

In this study, significant loss of motor function was found among elderly people who had relocated to privately rented temporary housing/rental housing after the GEJE, in comparison with those who had continued to live in the same housing as that before the disaster. This suggests that if relocation is necessary after a disaster, rehousing policies should ensure that elderly people retain their social capital.

Acknowledgements We would like to thank Yoshiko Nakata, Yumi Tamura, Fukuko Kano, Mao Suzuki and Mami Takahashi for their technical assistance.

Contributors KI, YT and IT conceived and designed the study. KI, YT, MK YS, TW and IT collected the data. KI and YT analysed the data. KI and YT drafted the article. MK, YS, TW, TA and IT revised the article and reviewed the draft.

Funding This work was supported by Health Sciences Research grants (H24, H25-Kenki-Shitei-002 (Fukkou)) from the Ministry of Health, Labour and Welfare of Japan

Competing interests None declared.

Patient consent Obtained.

Ethics approval This survey study was performed with the approval of the Institutional Review Board of Tohoku University Graduate School of Medicine. The survey participants provided written, informed consent after being provided a written and oral explanation of the study contents.

Provenance and peer review Not commissioned; externally peer reviewed.

Data sharing statement No additional data are available.

Open Access This is an Open Access article distributed in accordance with the Creative Commons Attribution Non Commercial (CC BY-NC 4.0) license, which permits others to distribute, remix, adapt, build upon this work noncommercially, and license their derivative works on different terms, provided the original work is properly cited and the use is non-commercial. See: http:// creativecommons.org/licenses/by-nc/4.0/

\section{REFERENCES}

1. World Health Organization. Older persons in emergencies: an active aging perspective. Geneva: World Health Organization, 2008.

2. Lin MR, Huang W, Huang $C$, et al. The impact of the Chi-Chi earthquake on quality of life among elderly survivors in Taiwan--a before and after study. Qual Life Res 2002;11:379-88.

3. Ardalan A, Mazaheri M, Mowafi $\mathrm{H}$, et al. Impact of the 26 December 2003 Bam Earthquake on activities of daily living and instrumental activities of daily living of older people. Prehosp Disaster Med 2011;26:99-108.

4. Tomata Y, Kakizaki M, Suzuki Y, et al. Impact of the 2011 Great East Japan Earthquake and Tsunami on functional disability among older people: a longitudinal comparison of disability prevalence 
among Japanese municipalities. J Epidemiol Community Health 2014;68:530-3.

5. Fire and Disaster Management Agency. About the Great East Japan Earthquake in 2011 (No.150). http://www.fdma.go.jp/bn/higaihou/pdf/ jishin/150.pdf (accessed 20 Jan 2016). Japanese.

6. Reconstruction Agency. Current state of the reconstruction. http:// www.reconstruction.go.jp/topics/main-cat1/sub-cat1-1/20140530 genjyo.pdf (accessed 20 Jan 2016). Japanese.

7. Uscher-Pines L. Health effects of relocation following disaster: a systematic review of the literature. Disasters 2009;33:1-22.

8. Giuliani AR, Mattei A, Santilli F, et al. Well-being and perceived quality of life in elderly people displaced after the earthquake in L'Aquila, Italy. J Community Health 2014;39:531-7.

9. DeSalvo KB, Hyre AD, Ompad DC, et al. Symptoms of posttraumatic stress disorder in a New Orleans workforce following Hurricane Katrina. J Urban Health 2007;84:142-52.

10. Miyagi Prefectural Government. Summary of the results of the health survey for residents living in privately-rented temporary housing in 2011. http://www.pref.miyagi.jp/uploaded/life/277726_348096_misc. pdf (accessed 20 Jan 2016). Japanese.

11. Kuriyama S, Nakaya N, Ohmori-Matsuda K, et al. Factors associated with psychological distress in a community-dwelling Japanese population: the Ohsaki Cohort 2006 Study. J Epidemio 2009;19:294-302.

12. WHO Regional Office for the Western Pacific. The Great East Japan Earthquake: a story of a devastating natural disaster, a tale of human compassion. Manila: WHO Regional Office for the Western Pacific, 2012.

13. Miyagi Prefectural Government. The outline of emergency temporary housing (prefabricated temporary housing). http://www.pref.miyagi.jp/ soshiki/engo/prefab.html (accessed 20 Jan 2016). Japanese.

14. Motoya R. Health promotion for the victims and evacuees of the Great East Japan Earthquake. Japanese J Behav Med 2013;19:68-74. Japanese.

15. Tsutsui $\mathrm{N}$. The study of life supports for victims living in temporary houses in the Great East Japan Earthquake: the role and challenges required for life support adviser. Ryukoku daigaku syakai gakubu kiyou 2013;42:54-67. Japanese.

16. Vogel T, Brechat PH, Leprêtre PM, et al. Health benefits of physical activity in older patients: a review. Int J Clin Pract 2009;63:303-20.

17. Miyagi Prefectural Government. The basic mechanism of emergency temporary housing (privately-rented temporary housing). http://www. pref.miyagi.jp/site/ej-earthquake/minchin-s.html (accessed 20 Jan 2016). Japanese.

18. Tomata $\mathrm{Y}$, Hozawa A, Ohmori-Matsuda $\mathrm{K}$, et al. [Validation of the Kihon Checklist for predicting the risk of 1-year incident long-term care insurance certification: the Ohsaki Cohort 2006 Study]. Nihon Koshu Eisei Zasshi 2011;58:3-13. Japanese.

19. Nemoto M, Yabushita N, Seino S, et al. Identification of the physical function of frail older adults and effectivity of the health check-up questionnaire (Kihon check-list). Japanese J Phys Fitness Sports Med 2011;60:413-22. Japanese.

20. Seino S, Yabushita N, Kim M, et al. The meaning and problem of understanding the subjects who participate in the program 'improvement of the motor function' using the Kihon checklist: considering from evaluation according to 'ability' and 'aspects of practice'. J Health Welfare Stat 2009;56:23-31. Japanese.

21. Soldatos CR, Dikeos DG, Paparrigopoulos TJ. The diagnostic validity of the Athens Insomnia Scale. J Psychosom Res 2003;55:263-7.

22. Soldatos CR, Dikeos DG, Paparrigopoulos TJ. Athens Insomnia Scale: validation of an instrument based on ICD-10 criteria. J Psychosom Res 2000;48:555-60.

23. Kessler RC, Barker PR, Colpe LJ, et al. Screening for serious mental illness in the general population. Arch Gen Psychiatry 2003;60:184-9.

24. Kessler RC, Andrews G, Colpe LJ, et al. Short screening scales to monitor population prevalences and trends in non-specific psychological distress. Psychol Med 2002;32:959-76.

25. Lubben J, Blozik E, Gillmann G, et al. Performance of an abbreviated version of the Lubben Social Network Scale among three European community-dwelling older adult populations. Gerontologist 2006;46:503-13.

26. Kurimoto A, Awata S, Ohkubo T, et al. [Reliability and validity of the Japanese version of the abbreviated Lubben Social Network Scale]. Nihon Ronen Igakkai Zasshi 2011;48:149-57. Japanese.

27. Murakami H, Yoshimura E, Ishikawa-Takata K, et al. Validity and reproducibility of a physical activity questionnaire used for health surveying among victims of the Great East Japan Earthquake. Nihon Koshu Eisei Zasshi 2013;60:222-30. Japanese.

28. Frison L, Pocock SJ. Repeated measures in clinical trials: analysis using mean summary statistics and its implications for design. Stat Med 1992;11:1685-704.

29. Cramer D, Howitt D. The SAGE dictionary of statistics: a practical resource for students in the social sciences. London: SAGE Publications, 2004:21.

30. Ueshima K, Fujiwara T, Takao S, et al. Does social capital promote physical activity? A population-based study in Japan. PLOS ONE 2010;5:e12135.

31. Greiner KA, Li C, Kawachi I, et al. The relationships of social participation and community ratings to health and health behaviors in areas with high and low population density. Soc Sci Med 2004;59:2303-12.

32. Miyagi Prefectural Government. The example of efforts of daily life support for victims in the Great East Japan Earthquake. http://www. pref.miyagi.jp/soshiki/hohusom/jirei.html (accessed 20 Jan 2016) Japanese.

33. Daniels R, van Rossum E, de Witte $L$, et al. Interventions to prevent disability in frail community-dwelling elderly: a systematic review. BMC Health Serv Res 2008;8:278. 